OPEN ACCESS

Edited by:

Haibin Shi,

Soochow University, China

Reviewed by:

Li-Jen Liao,

Far Eastern Memorial Hospital, Taiwan

Ping Zhou,

Central South University, China

*Correspondence:

Xin-Wu Cui

cuixinwu@/ive.cn

Ai-Jiao Y

938186822@163.com

${ }^{\dagger}$ These authors have contributed equally to this work

Specialty section: This article was submitted to Cancer Imaging and Image-directed Interventions,

a section of the journal

Frontiers in Oncology

Received: 25 May 2021

Accepted: 26 July 2021

Published: 17 August 2021

Citation:

Wang B, Guo Q, Wang J-Y, Yu Y,

YiA-J, Cui X-W and Dietrich CF (2021)

Ultrasound Elastography for the

Evaluation of Lymph Nodes.

Front. Oncol. 11:714660.

doi: 10.3389/fonc.2021.714660

\section{Ultrasound Elastography for the Evaluation of Lymph Nodes}

\author{
Bin Wang ${ }^{1 \dagger}$, Qi Guo ${ }^{2+}$, Jia-Yu Wang ${ }^{3}$, Yang $\mathrm{Yu}^{3}$, Ai-Jiao $\mathrm{Yi}^{{ }^{*}}{ }^{*}$, Xin-Wu Cui ${ }^{{ }^{*}}$ \\ and Christoph F. Dietrich ${ }^{4}$
}

${ }^{1}$ Department of Ultrasound, The First People's Hospital of Yueyang, Yueyang, China, ${ }^{2}$ Department of Medical Ultrasound, The Fifth Affiliated Hospital of Zhengzhou University, Zhengzhou, China, ${ }^{3}$ Department of Medical Ultrasound, Tongji Hospital, Tongji Medical College, Huazhong University of Science and Technology, Wuhan, China, ${ }^{4}$ Department of Internal Medicine, Hirslanden Clinic, Bern, Switzerland

The differential diagnosis of lymphadenopathy is important for predicting prognosis, staging, and monitoring the treatment, especially for cancer patients. Conventional computed tomography and magnetic resonance imaging characterize lymph node $(L N)$ with disappointing sensitivity and specificity. Conventional ultrasound with the advantage of high resolution has been widely used for the LN evaluation. Ultrasound elastography (UE) using color map or shear wave velocity can non-invasively demonstrate the stiffness and homogeneity of both the cortex and medulla of LNs and can detect early circumscribed malignant infiltration. There is a need of a review to comprehensively discuss the current knowledge of the applications of various UE techniques in the evaluation of LNs. In this review, we discussed the principles of strain elastography and shear wave-based elastography, and their advantages and limitations in the evaluation of LNs. In addition, we comprehensively introduced the applications of various UE techniques in the differential diagnosis of reactive LNs, lymphoma, metastatic LNs, and other lymphadenopathy. Moreover, the applications of endoscopic UE and endobronchial UE are also discussed, including their use for improving the positive rate of diagnosis of fine-needle aspiration biopsy.

Keywords: lymph nodes, screening, ultrasonography, elastography, shear wave

\section{INTRODUCTION}

Various benign and malignant disorders can result in lymphadenopathy; the differential diagnosis of lymph node (LN) is important for predicting prognosis, staging, and monitoring the treatment. Conventional computed tomography (CT) and magnetic resonance imaging (MRI) characterize LN relying on size and topographic distribution, but with disappointing sensitivity and specificity, since it is not rare that malignant LN infiltration occurs in normal-sized LN.

Conventional ultrasound (US) with the advantage of high resolution has been widely used for imaging superficial organs, particularly for the LN evaluation. Compared with conventional CT and MRI, B-mode US can provide more detailed information on shape, contour, inner texture, maximum short axis diameter, long to short axis ratio, absence of hilus, and presence of necrosis. Color Doppler US and spectral Doppler US can image the hemodynamic characters of LN and add values for the differentiation of malignant from benign LNs. Benign LNs often show hilar predominant vessel 
architecture and have lower resistive index (RI), while malignant LNs usually show peripheral or mixed vascularity and disappearance of hilar vascularization and have higher RI. However, Doppler techniques have limitations in small LN since the vascularity is often undetectable (Figures 1-3).

US elastography (UE) is a new technique that uses color map or shear wave velocity (SWV) to non-invasively demonstrate stiffness and homogeneity. It has rapidly become one of the most popular US-based techniques. Clinically, it can be used in the early detection and differential diagnosis of focal diseases; in improving the accuracy for diagnosing diffuse diseases, such as fibrosis and atherosclerosis; and in the assessment of response to treatments, such as thermal ablation and chemotherapy (1).

UE is able to demonstrate the stiffness of both the cortex and medulla of LNs and to detect early circumscribed malignant infiltration. Studies have been published on the evaluation of LNs by strain elastography (SE) or shear wave elastography (SWE). This review aims to comprehensively discuss the current knowledge of the applications of various UE techniques in the evaluation of LNs.

\section{PRINCIPLES AND TECHNIQUES OF ULTRASOUND ELASTOGRAPHY}

UE is a technique in which the stiffness of the tissue can be imaged as color map or SWV. The principle of UE is based upon tissue reactions, such as changes in displacement, strain, or speed, by applying an external or internal static (quasi-static) or dynamic excitation. Differences in tissue reactions are calculated, identified, and reflected by computers.

Depending on the type of excitation applied, UE is classified into two categories, i.e., 1) SE, which is composed of static or quasi-static strain imaging and acoustic radiation force impulse (ARFI) imaging; and 2), SWE which is composed of SWV measurement and SWV imaging (Figure 4).

\section{Strain Elastography}

\section{Technique}

SE includes static/quasi-static imaging and ARFI imaging. It is based upon the fact that hard tissue is more difficultly compressed than soft tissue. SE is a technique that measures

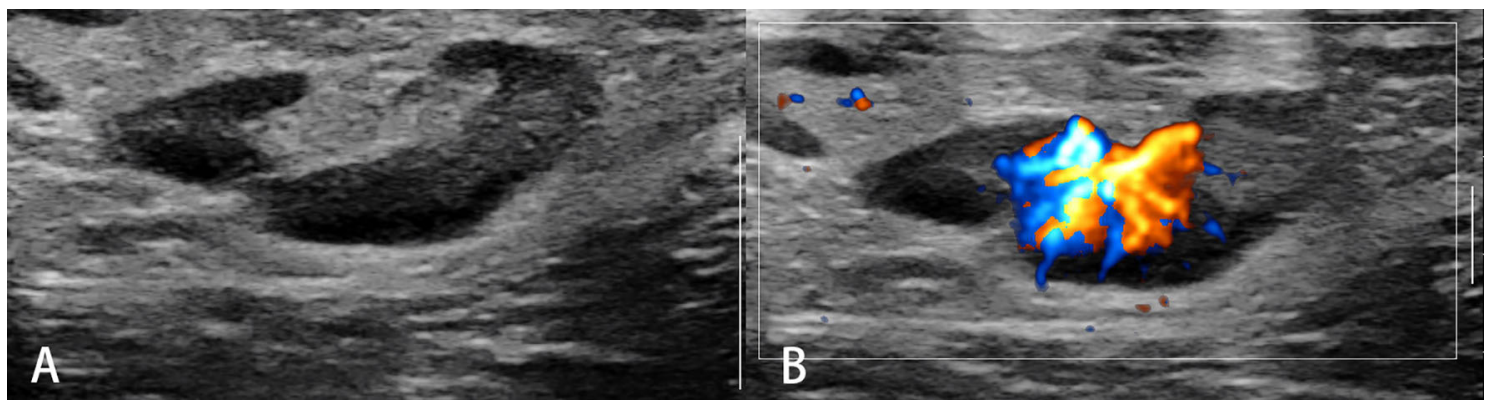

FIGURE 1 | Reactive lymph nodes. Typically, the architecture (A) and predominant vessel architecture (B) are preserved.

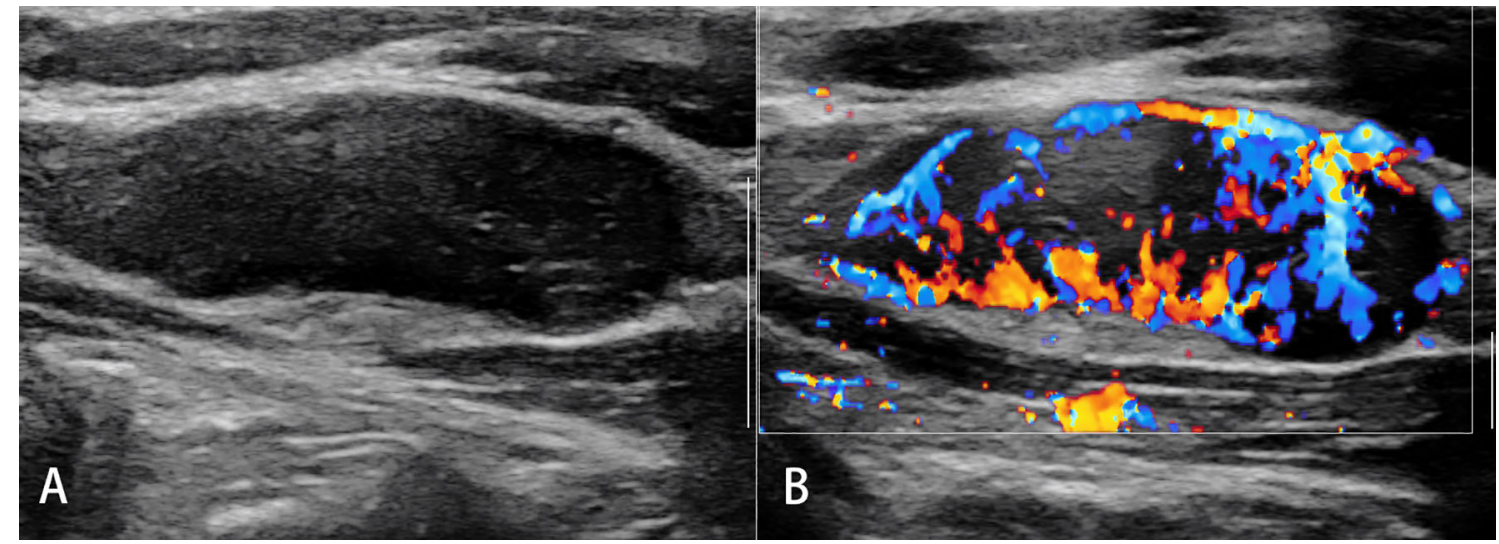

FIGURE 2 | Malignant lymph nodes (carcinoma infiltration). The eccentric hypoechoic cortical thickening (A) and vessel destruction (B) in the lymph node are observed. 


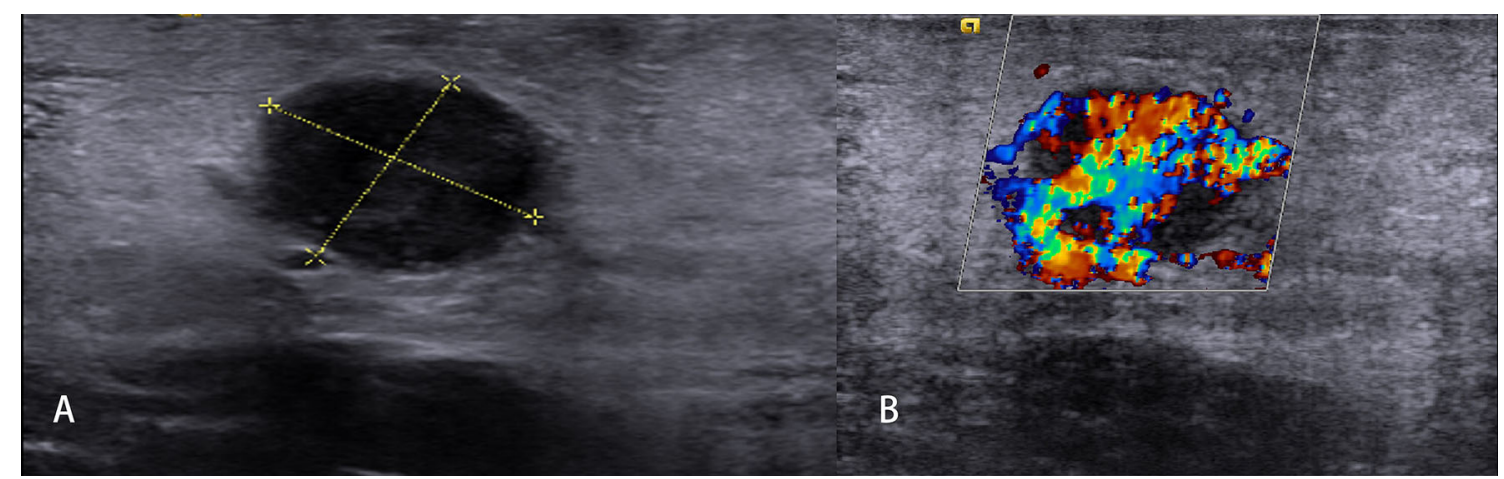

FIGURE 3 | Non-Hodgkin's lymphoma. The destroyed architecture, approximate sphere, and pseudocystic appearance (A) and rich vascularity (B) are observed.

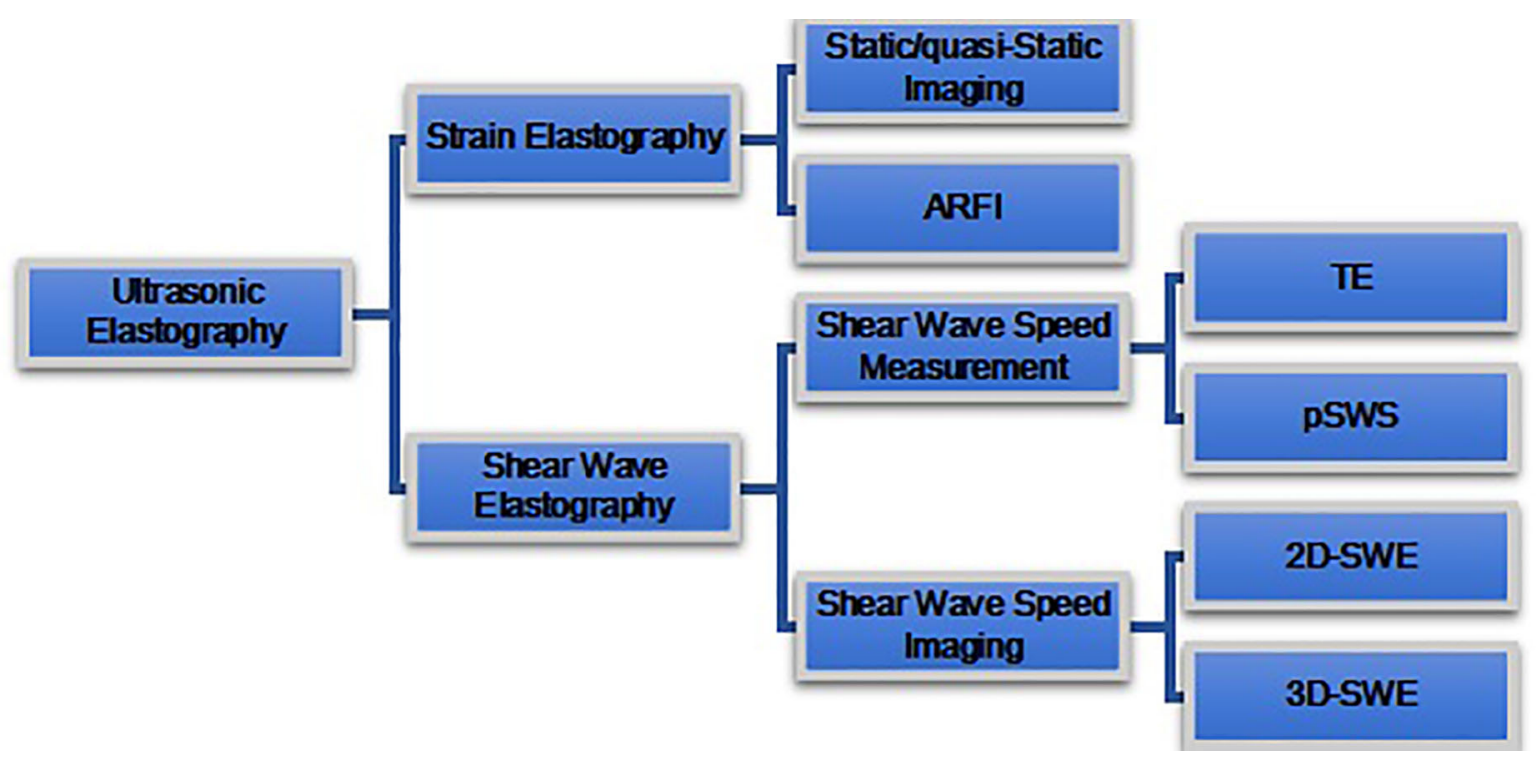

FIGURE 4 | Ultrasound elastography (UE) techniques. UE techniques can be classified by the type of excitation applied: 1) strain elastography (top) and 2) shear wave elastography (bottom). Excitation methods of strain elastography include constant force-induced displacement (static/quasi-static imaging) or acoustic energyinduced physiologic motion (ARFI). Excitation method of shear wave elastography where the shear waves are produced by a transducer. Shear wave elastography is classified as transient elastography (TE), point shear wave elastography (pSWE), two-dimensional shear wave elastography (2D-SWE), and three-dimensional shear wave elastography (3D-SWE), according to different measurement and imaging methods.

the tissue deformation generated by compression, which may be applied with a probe on the body surface for static/quasi-static imaging and may also be applied with acoustic radiation force for ARFI imaging. The tissue deformation is measured by US system and displayed as a color or gray map. On the screen of the US system, both the B-mode image and corresponding elastography image could be simultaneously displayed.

The parameters commonly used to indicate tissue hardness include elasticity score and strain ratio (SR). The elasticity score indicates the strain (with color or brightness) distribution within a selected area. The SR refers to the ratio of strain between area A (usually a mass) and area B (usually a normal surrounding tissue, fat, or muscle tissue) within the region of interest (ROI).

\section{Advantages and Limitations}

$\mathrm{SE}$, especially static/quasi-static imaging, is suitable for superficial organs and thus is the most commonly used method for the evaluation of superficial LNs. The operation method of SE is simple, and the operation skills can be mastered in a short time of training. However, SE is a qualitative analysis technique, and it is not able to analyze tissue hardness quantitatively. The performance of static/quasi-static imaging 
is not good at analyzing the deep LNs. Moreover, SE is user dependent and subjective $(2,3)$.

\section{Shear Wave Speed Measurement}

\section{Techniques}

Shear wave speed measurement technology is a method to generate shear waves and measure SWV. Based on the principle of fast propagation of shear wave speed in hard tissue and slow propagation in soft tissue, the hardness of tissue is indirectly reflected by measuring shear wave speed. Shear wave speed can be converted to Young's modulus by Young's model formula:

$$
\mathrm{E}=3 \rho \mathrm{C}^{2}
$$

where E represents stiffness (Young's modulus $[\mathrm{kPa}]$ ), $\rho$ is the density $\left(\mathrm{kg} / \mathrm{m}^{3}\right.$, approximately equal to 1$)$, and $\mathrm{C}$ is the shear wave speed $(\mathrm{m} / \mathrm{s})$.

The shear wave speed measurement techniques mainly include transient elastography (TE) and point SWE (pSWE). TE is the first shear wave speed measurement technology applied in clinical practice, but it is only used in the liver so far; therefore, this technique is not discussed in this review. The principle of pSWE is similar with ARFI: the probe applies an acoustic radiation force to the $\mathrm{ROI}$ of the tissue and generates transverse vibration shear waves. The receiver can detect the speed of shear wave in ROI, which is expressed by speed or by $\mathrm{kPa}$ value through Young's model formula.

\section{Advantages and Limitations}

pSWE can detect both deep organs (the liver, etc.) and superficial organs (the thyroid, etc.) (4-6), and therefore, this technique is suitable for both superficial and deep LNs. However, the ROI is with fixed size; it can only measure one part of a LN but may be too large if the LN is very small.

\section{Shear Wave Speed Imaging}

\section{Techniques}

The principles of shear wave speed imaging are that the US probe sends out the multipoint focused acoustic radiation force pulse, which makes the tissues at different depths along with the acoustic axis shift at almost the same time, producing plane shear wave, and then the image processing technology detects the SWV, forms color image, and calculates Young's modulus (elasticity index (EI)) (7). So compared with that of pSWE, the size of ROI in 2D-SWE can be adjustable. Some US diagnostic instruments are equipped with $3 \mathrm{D}$ probes with high-speed acquisition capability of mechanical scanning 2D-sensor sequences, which can conduct $3 \mathrm{D}$ reconstruction of tissue hardness.

\section{Advantages and Limitations}

The diagnosis of shear wave speed imaging is less influenced by the operator's experience and operation than SE, because it does not rely on freehand compression (8). It can display the conventional US images and elastic US images synchronously and measure SWV in real time. However, multicenter studies have shown that the repeatability of shear wave elastic imaging is affected by the size, location, depth, and other factors $(9,10)$.

\section{CLINICAL APPLICATIONS OF ELASTOGRAPHY}

\section{Reactive Lymph Nodes (Inflammation)}

Acute or chronic inflammation is the prime cause of $\mathrm{LN}$ enlargement (Figure 5). The elastographic architecture of LNs is kept in most inflammatory processes. Therefore, like in normal LNs, the cortex is also stiffer than the hilum in inflammatory LNs.

\section{Strain Elastography}

Both elasticity score and SR have been studied to evaluate the stiffness of reactive LN. Firstly, due to the lack of a unified classification method for US elastograms, different researchers classified US elastograms of LNs into a 4-point, 5-point, 6-point, 7-point, or 8-point rating scale. Secondly, some researchers compared the strain in target region with adjacent reference region to differentiate benign from malignant LNs.

Lyshchik classified US elastograms of LNs with a 4-point rating scale according to visibility, brightness compared with surrounding neck muscles, regularity, and definition of outline (11). Several studies classified elastograms of the LNs into five patterns according to relative distribution and ratio of soft or hard regions of the LN: pattern 1, absent or very small blue (hard) areas; pattern 2, total blue areas of less than $45 \%$; pattern 3 , total blue areas of greater than $45 \%$; pattern 4 , peripheral blue

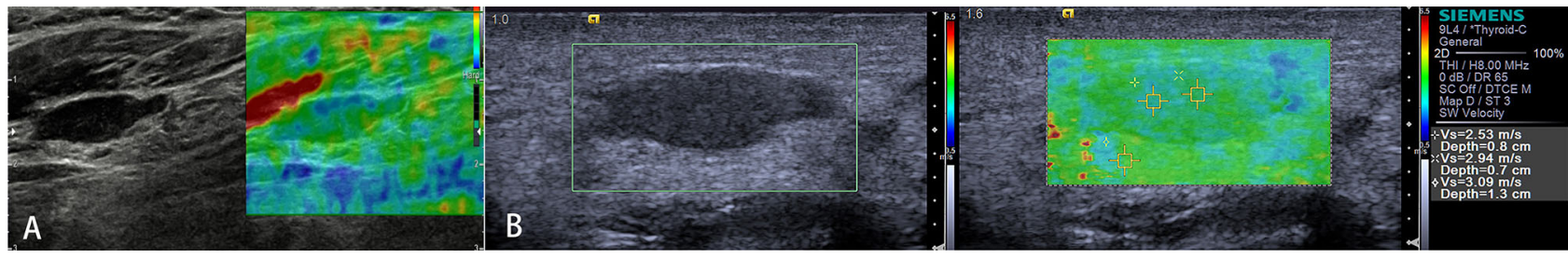

FIGURE 5 | Reactive lymph nodes. Both the strain elastography (A) and shear wave-based elastography (B) reveal uniform and symmetrical soft tissue (green). 
area and central green (soft) area; and pattern 5, blue area with or without a green rim. Tan et al. found that $87.9 \%$ of benign LNs manifest pattern 1 or pattern 2 (3).

Besides, Lyshchik defined the surrounding neck muscles to LN SR as strain index; using strain index value of $<1.5$ in benign LN classification, SE showed $79 \%$ accuracy, $85 \%$ sensitivity, and 98\% specificity (11). Acu et al. calculated each LN with mean strain index. With the use of strain index value of $<1.7, \mathrm{SE}$ differentiates benign LNs from malignant ones with $75 \%$ accuracy, $71.6 \%$ sensitivity, and $76.5 \%$ specificity (12). Özel et al. reported that elastography SRs were lower in benign LNs than malignant LNs (13). Many studies have shown that SE has potential diagnostic value in lymphadenopathy (Table 1); however, high user dependence is the limitation, especially using SR. Adjacent reference region was selected differently for SR measurement of LNs in different regions; in general, muscles as adjacent reference tissues were usable in cervical region, and fat tissue as an adjacent reference region may be a good choice in the axilla.

\section{Shear Wave-Based Elastography}

Compared with SE, shear wave-based elastography is regarded as potentially more objective. In most published researches, virtual touch tissue imaging (VTI) grade and SWV of ARFI imaging were used to evaluate reactive LNs, and the diagnostic performance of VTI is higher than that of SWV (19). In a study including 263 pediatric LNs, Bayramoglu et al. found that median elasticity and velocity values were higher in reactive LNs compared with normal LNs; with the use of the cutoff median elasticity and velocity values of $>15 \mathrm{kPa}$ and $2.24 \mathrm{~m} \mathrm{sn}^{-1}$ for differentiating reactive LNs from normal LNs, sensitivity, specificity, positive predictive value (PPV), negative predictive value (NPV), and diagnostic accuracy were $27 \%, 96 \%, 82 \%, 74 \%$, and $74 \%$ and $25 \%, 97 \%, 82 \%, 73 \%$, and $74 \%$, respectively. Many studies should be conducted on the evaluation of reactive LNs by shear wave-based elastography to explore the significance of SWE in the evaluation of reactive LNs and to analyze the potential factors affecting SWE imaging (24).

\section{Malignant Lymph Nodes (Carcinoma)}

Malignant tumor cells proliferate rapidly, causing internal pressure and increasing tissue stiffness in LNs. Therefore, the elastographic architecture of LNs changed compared with reactive LNs. Typically, the well-differentiated carcinoma initially infiltrates LNs in a circumscribed manner (focally stiffer and harder), whereas the undifferentiated carcinoma leads to a diffuse (mostly or completely stiffer and harder) infiltration (Figure 6).

\section{Strain Elastography}

Several pilot studies have evaluated the ability of SE to detect LN metastases in the cervical or axillary LNs (11, 14, 20-22, 27). Both elasticity score and SR have been studied, which showed that SE and conventional US may play complementary roles in

TABLE 1 | The diagnostic performance of ultrasound elastography in differentiating benign and malignant LNs.

\begin{tabular}{|c|c|c|c|c|c|c|c|c|}
\hline Study & Study description & LN & $\begin{array}{l}\text { SE } \\
(\%)\end{array}$ & $\begin{array}{l}\text { SP } \\
(\%)\end{array}$ & $\begin{array}{l}\text { PPV } \\
(\%)\end{array}$ & $\begin{array}{l}\text { NPV } \\
(\%)\end{array}$ & Accuracy & Gold standard \\
\hline Lo WC, European Radiology (14) & Qualitative (4 patterns) & 131 & 66.7 & 57.1 & 52.2 & 71.0 & - & Histology \\
\hline Suzan Onol, Cureus (15) & Qualitative (4 scores) & 70 & 94 & 70 & - & - & 86 & Histology \\
\hline Leyla Acu, J Ultrasound Med (12) & Qualitative (5 patterns) & 220 & 82.1 & 56.2 & 45.1 & 87.8 & 64.1 & Histopathology \\
\hline $\begin{array}{l}\text { Tsai WC, Ultrasound in Medicine \& } \\
\text { Biology (16) }\end{array}$ & Qualitative (5 patterns) & 90 & 86 & 90 & 91 & 84 & 88 & Surgical pathology \\
\hline Xu Y, Scientific Reports (17) & Qualitative (5 patterns) & 97 & 78 & 93 & 93 & 79 & 86 & Surgical pathology \\
\hline $\begin{array}{l}\text { Müberra Pehlivan, Braz J } \\
\text { Otorhinolaryngol (18) }\end{array}$ & Qualitative (5 patterns) & 16 & 82.4 & 84.6 & 87 & 78 & 83.3 & Histology \\
\hline Zhang F, Medicine (Baltimore) (19) & Qualitative (6 patterns) & 97 & 81.58 & 95.65 & - & - & 86.89 & Histology \\
\hline $\begin{array}{l}\text { Lenghel LM, Medical } \\
\text { Ultrasonography }(20)\end{array}$ & Qualitative (8 patterns) & 69 & 66.7 & 96.7 & - & - & 84.6 & Follow-up, histology \\
\hline Lyshchik A, Radiology (11) & Quantitative (strain index $\geq 1.5$ ) & 141 & 85 & 98 & - & - & 92 & Histology \\
\hline Leyla Acu, J Ultrasound Med (12) & Quantitative (strain index $\geq 1.7$ ) & 220 & 71.6 & 76.5 & 57.1 & 86.0 & 75.0 & Histopathology \\
\hline $\begin{array}{l}\text { Müberra Pehlivan, Braz J } \\
\text { Otorhinolaryngol (18) }\end{array}$ & Quantitative (strain index $\geq 1.04$ ) & 16 & 100 & 84.62 & - & - & 95 & Histology \\
\hline Zhang F, Medicine (Baltimore) (19) & Quantitative (SWV $\geq 2.76$ m) & 97 & 57.89 & 86.96 & - & - & 68.85 & Histology \\
\hline $\begin{array}{l}\text { Fujiwara T, Ultrasound in Medicine } \\
\text { \& Biology (21) }\end{array}$ & Quantitative (SWV $\geq 1.9$ m/s) & 42 & 95.0 & 81.8 & - & - & 88.0 & $\begin{array}{l}\text { Surgical pathology, Lymph node } \\
\text { open biopsy }\end{array}$ \\
\hline $\begin{array}{l}\text { Meng W, European Journal of } \\
\text { Radiology (22) }\end{array}$ & Quantitative (VTIQ value $\geq 2.595$ m/s) & 181 & 82.9 & 93.1 & - & - & 90.6 & $\begin{array}{l}\text { Surgical pathology, fine-needle } \\
\text { aspiration }\end{array}$ \\
\hline $\begin{array}{l}\text { Azizi G, Ultrasound in Medicine \& } \\
\text { Biology (23) }\end{array}$ & Quantitative (VTIQ value $\geq 2.93$ m/s) & 270 & 92.59 & 75.49 & 48.54 & 97.60 & 78.9 & Surgical pathology \\
\hline Zuhal Bayramoglu, Br J Radiol (24) & $\begin{array}{l}\text { Quantitative (elasticity > } 17 \text { kPa) (lymphoma } \\
\text { vs. Iymphadenitis) }\end{array}$ & 117 & 96 & 100 & 100 & 99 & 99 & Histology \\
\hline Shuyi Luo, Front Oncol (25) & Qualitative SWE (4 scores) & 121 & 96.7 & 100 & 100 & 96.8 & 98.3 & $\begin{array}{l}\text { Core needle biopsy, surgical } \\
\text { pathology }\end{array}$ \\
\hline Wei Lin Ng, Acad Radiol (26) & Qualitative SWE (4 scores) & 107 & 96.0 & 56.1 & - & - & 81.3 & Histopathology \\
\hline
\end{tabular}

LNs, lymph nodes; SE, sensitivity; SP, specificity; PPV, positive predictive value; NPV, negative predictive value; SWV, shear wave velocity; VTIQ, virtual touch tissue imaging quantification; SWE, shear wave elastography. 

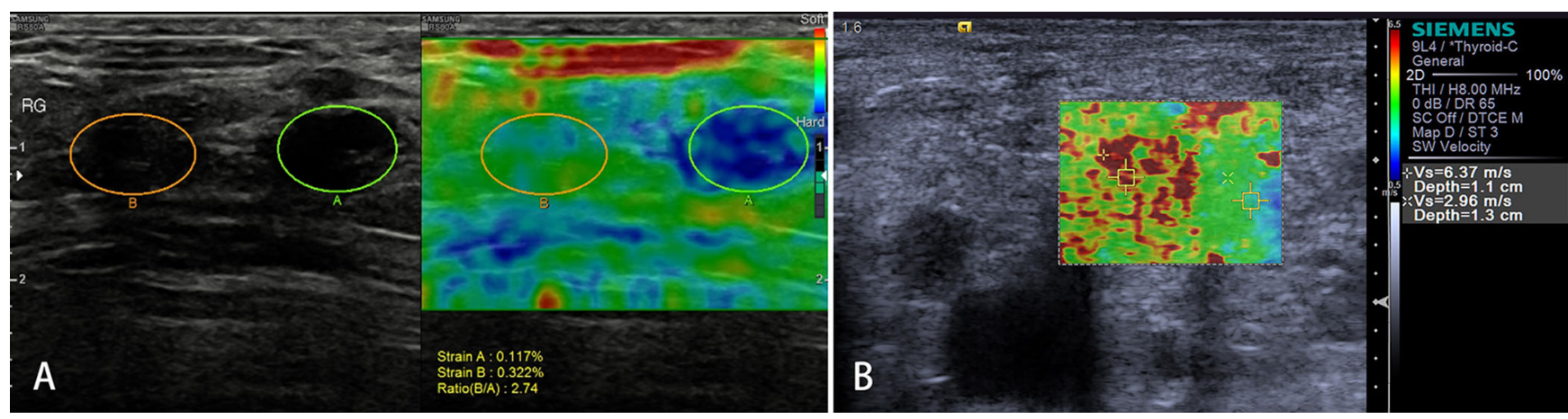

FIGURE 6 | Malignant lymph nodes (LNs) (carcinoma infiltration). The strain elastography reveals typically harder (blue) area in the LN than the surrounding tissues (green); strain ratio $=2.74$ (A). The shear wave-based virtual touch tissue imaging quantification reveals a harder (red) area in the LN, and the maximum shear wave velocity $(6.37 \mathrm{~m} / \mathrm{s})$ is much higher than that of surrounding tissues $(2.96 \mathrm{~m} / \mathrm{s}) \mathbf{( B )}$.

differentiating malignant LNs and assessing the risk of metastatic LNs.

Firstly, suspected cervical LN metastases from hypopharyngeal and thyroid carcinomas have been recently investigated using SE (real-time elastography (RTE)) (11). An EI has been created by comparing the elasticity of the LN with the surrounding head and neck muscle tissue (muscle to LN SR). With the use of a ratio of $>1.5$ as an indicator of malignant infiltration, the sensitivity was $85 \%$ and the specificity was $98 \%$, which are superior to the best B-mode criteria (11). These data have been reproduced by Tan et al. Moreover, inter-observer agreement with SE was very high (kappa 0.88-0.946) (3).

Secondly, some researchers qualitatively classified US elastograms of LNs into a 4-point, 5-point, 6-point, 7-point, or 8-point rating scale. Metastatic LNs were mostly evaluated to 3-4 points in a 4-point rating scale. Suzan (15) found that the sensitivity, specificity, and accuracy of RTE in differentiating benign LN from squamous cell carcinoma and malignant melanoma group were $91 \%, 70 \%$, and $86 \%$, respectively.

In a 5 -point rating scale $(3,12,16,18)$, Tan et al. reported that 50 of malignant and $74.5 \%$ of metastatic LNs manifested pattern 3 or 4, while all primary malignant LNs manifested pattern 2 (3). In another study including 97 axillary LNs, using the criteria of score 1 and 2 as benign and scores 3, 4, and 5 as metastatic, the sensitivity, specificity, PPV, NPV, and accuracy were 78\%, 93\%, $93 \%, 79 \%$, and $86 \%$, respectively (16). Although qualitative strain methods based on elasticity score and SR have been widely studied all over the world for axillary and cervical LNs (17), SR $>1.5$ or hard composition over $50 \%$ can be a good indicator of malignancy. However, as compared with SWE, its dependence on operators cannot be overcome, and absolute quantitative elastic measurement cannot be provided; and for LNs with deep vertical distance and small volume, the judgment of RTE on LNs hardness is prone to false-positive results, which affects the accuracy of SE (16).

\section{Shear Wave-Based Elastography}

Clinically and theoretically, SWE seems to be an effective, quantitative tool for differential diagnosis of malignant and benign LNs in many researches, especially in small LNs (28). Based on previous researches, the maximum SWV $(2.93 \mathrm{~m} / \mathrm{s})$ (23) and elastic value ratio (29) can be used as reliable indices to predict benign and malignant lymphatic nodes. Kılıç A et al. conducted a prospective study comparing conventional US with VTI quantification (VTIQ), and when using a cutoff value of 3.03 $\mathrm{m} / \mathrm{s}$, VTIQ differentiates malignant LNs from benign ones with $75 \%$ accuracy, 93\% sensitivity, and 59\% specificity (30).

Some researchers $(25,26)$ qualitatively classified SWE images of axillary LN (ALN) into 4-point patterns, which was similar to SWE patterns of breast lesions (31): color pattern 1, homogeneous pattern; color pattern 2, filling defect within LN; color pattern 3 , homogeneous within LN with a localized colored area at the margin; and color pattern 4, filling defect within LN with a localized colored area at the margin (25). The benign ALNs usually manifest color pattern 1, while ALN metastases (ALNMs) usually manifest color patterns 2-4, and the sensitivity, specificity, PPV, NPV, and area under the receiver operating characteristic (ROC) curve (AUC) were 96.7\%, 100\%, 100\%, $96.8 \%$, and $98.3 \%$, respectively (25). In addition, Luo et al. (25) and Lin et al. (26) directly compared the diagnostic performance of qualitative and quantitative SWE, and they found that qualitative SWE had better diagnostic performance than quantitative SWE in detecting ALNM.

However, a meta-analysis compared the diagnostic performance of qualitative elastography with quantitative elastography for ALNM in breast cancer and found that quantitative and qualitative elastography had similar diagnostic performance and good clinical utility (32). More studies with SWE should be conducted to get more reliable cutoff values of SWV and elastic value ratio in different sites.

\section{Lymphoma}

Lymphomas are a primary malignant tumor of LNs, lymphoid tissues outside LNs, and mononuclear macrophage system (Figure 7). Because of a highly heterogeneous group of lymphoproliferative malignancies, the biological behavior and pathological types of lymphomas are different, especially for non-Hodgkin's lymphoma. But the incidence of lymphomas 


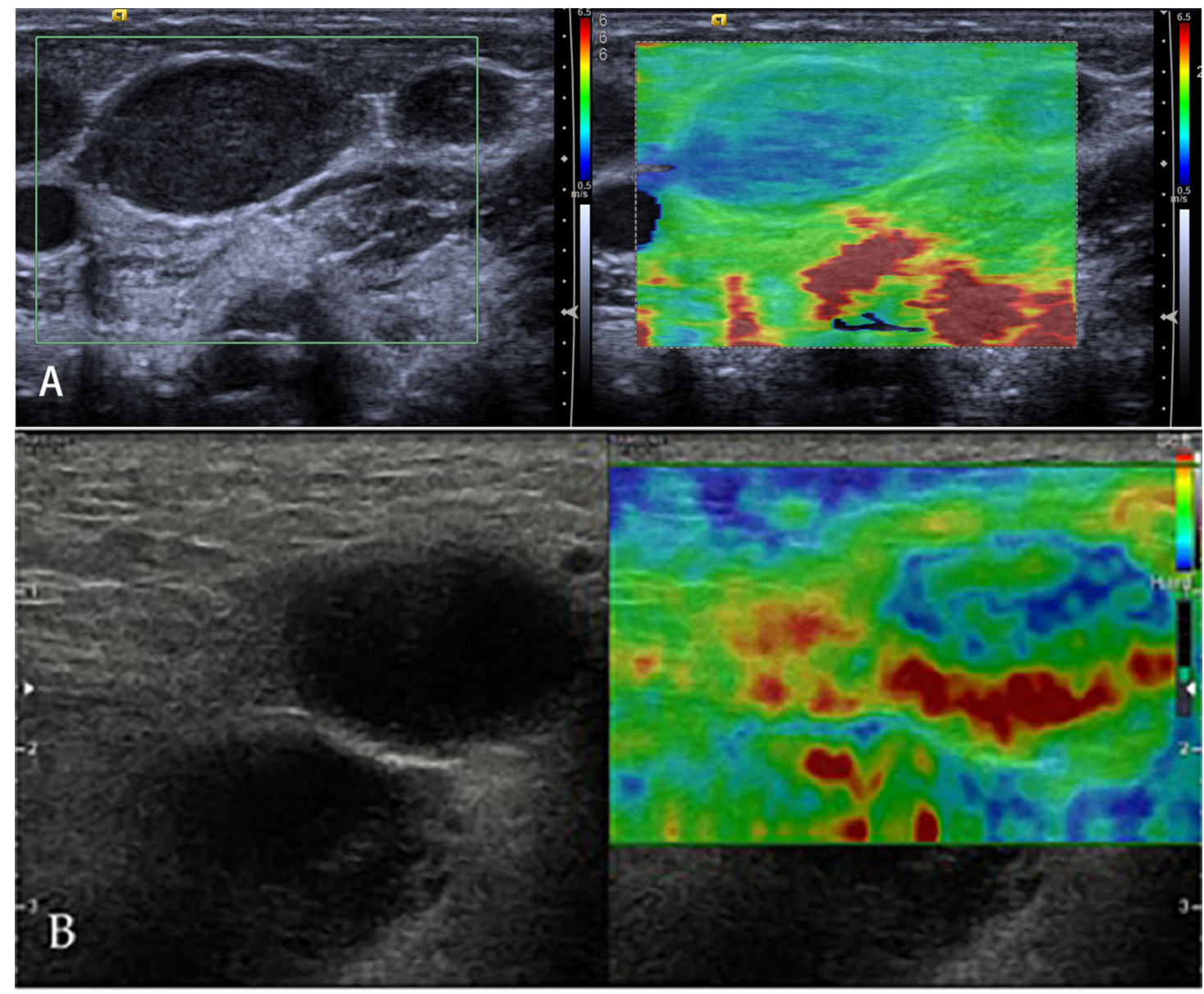

FIGURE 7 | Non-Hodgkin's lymphoma. The strain elastography reveals a focal harder (blue) area in the lymph node (A) and a diffuse harder (blue) area in the lymph node (B).

represents approximately 4\%, and newly diagnosed cancers increases each year; moreover, lymphomas are more commonly seen in developed countries, which may seriously endanger people's health (33). Knowledge of elastography in lymphoma is very limited. So far, different lymphomas cannot be differentiated. Initial experience suggests that focal LN infiltration (Figure 7A) is indicative of low-grade follicular lymphoma, whereas diffuse and homogenous LN infiltration is typically found in high-grade lymphoma (Figure 7B).

\section{Strain Elastography}

Few studies have reported on the evaluation of lymphoma with SE. With a 5-point rating scale of US elastograms of LNs, Acu et al. reported that most lymphoma manifested patterns 1 and 2 (16). Clinically and theoretically, the stiffness degree of lymphoma is different from that of metastatic and benign LNs (34). In most studies, the hardness of the lymphoma was low. Thus, when metastasis and lymphoma were considered as positive, reactive LNs were considered as negative in the differential diagnosis; and the sensitivity, specificity, and accuracy with a point rating scale of US elastograms were affected (35). With quantitative analysis of SE, elasticity parameter strain index showed high diagnostic accuracy for distinguishing lymphoma from lymphadenitis; the cutoff value of the strain index of the cervical LNs compared with sternocleidomastoid muscle has been reported to be 1.18 in a recent study (36). Though it is difficult to differentiate different lymphomas, the treatment effect evaluation with SE in Hodgkin's disease may be useful.

In the study on the efficacy of refractory and recurrent Hodgkin's disease, it has been shown that the hardness of some lymphoma nodules changes with the treatment effect. It indicates that SE could be reliable for therapy response monitoring of Hodgkin's lymphoma (37).

\section{Shear Wave-Based Elastography}

Currently, there are few studies on the evaluation of lymphoma by SWE. The number of enrolled lymphoma in these studies was small, including several case reports. Soo et al. qualitatively categorized shear speed map in a of total five SWE patterns in cervical LNs: pattern 1, absent or very small red (stiff) area; pattern 2, small scattered red areas, which mean total red area 
less than 45\%; pattern 3, large red area, equal or more than $45 \%$; pattern 4, peripheral red area and central green (soft) area, suggesting central necrosis; and pattern 5, almost red area with or without a green rim. None of lymphoma manifested pattern 4 and pattern 5; and absolute values and ratio of both elasticity and speed were significantly lower in lymphomas than metastatic LNs (38). Based on a recent study in pediatric LN with quantitative evaluation of SWE, elasticity values higher than 17 $\mathrm{kPa}$ and velocity values higher than $2.45 \mathrm{~m} / \mathrm{s}$ would be considered as lymphoma rather than lymphadenitis in an enlarged LN with at least a 91\% diagnostic accuracy (24). Several case reports have evaluated uncommon different lymphomas with SWE. A report used SWE to evaluate primary B-cell lymphoma of the breast. The study showed that the mass of primary B-cell lymphoma on SWE was considerably stiff but softer than typical invasive ductal cancers. In the future, a prospective study with large-scale samples should be conducted to investigate quantitative or qualitative SWE features of primary B-cell lymphoma (39).

\section{Other Lymphadenopathy}

In the preliminary study of reactive and metastatic LNs, the AUC for combined evaluation is 0.97 , which is much higher than that for B-mode US or elastography alone (28). The analysis of parameters can be used to quantitatively evaluate the characteristics of different LN diseases; it shows that LNs of tuberculosis (TB) are softer than metastatic LNs but harder than benign LNs (40). However, LNs of TB have a wide range of stiffness; the stiffness is related with internal structures, increased fibrous tissue and calcification can account for high stiffness, and liquefaction necrosis can decrease the stiffness. Cheng et al. found that only $50 \%$ LNs of TB can be correctly diagnosed by elastography (41).

In further studies, the combination of B-mode US and elastography may have important clinical value in differential diagnosis. Few researches have been done on relapsing or chronic lymphadenitis or rare benign diseases such as Kikuchi or Kimura disease $(\mathrm{KD})$. The research shows that the LNs with $\mathrm{KD}$ show malignant signs in conventional US, but benign signs in SE; therefore, SE can help patients avoid unnecessary needle biopsy and inappropriate treatment (42). In a study of children's cervical LNs, the stiffness of the largest LNs in patients with bacterial cervical lymphadenitis (BCL) was significantly higher than that in patients with LN-first presentation of Kawasaki disease (NFKD) and healthy children, with a cutoff of $14.55 \mathrm{kPa}$; the sensitivity, specificity, and AUC were $89 \%, 76 \%$, and $88.5 \%$, respectively (43). So SWE is a potential method to differentiate early NFKD.

\section{APPLICATIONS OF ENDOSCOPIC ULTRASOUND AND ENDOBRONCHIAL ULTRASOUND ELASTOGRAPHY}

Endoscopic US (EUS) and endobronchial US (EBUS) are important tools to assess the digestive tract and surrounding organs, but the limited capacity to determine the exact pathological results is the major limitation. As a non-invasive technique, EUS and EBUS elastography have been proven to be able to provide complementary stiff information added to conventional EUS and EBUS imaging, becoming promising examination methods to differentiate benign from malignant LNs (44-46).

\section{Differentiation of Benign and Malignant Lymph Nodes}

Recently, an increasing number of literatures focused on the use of EUS and EBUS to diagnose mediastinal LNs and peritoneal lymphadenitis.

EUS elastography was originally used for the differential diagnosis of pancreatic lesions. Studies on the difference between benign and malignant pancreatic masses and LNs by SE showed that EUS elastography had more advantages than conventional US (47).

Similar to superficial LNs, physiological and reactive peritoneal LNs manifest homogeneous or scattered soft pattern with delineated vascular structures of LN hilum. And the LN medulla may manifest as slightly softer than the LN cortex. Malignant LNs are the most characterized by a homogeneous hard elastographic pattern, especially in diffuse metastatic infiltration; however, malignant LNs may display inhomogeneous but hard patterns because of incomplete metastatic infiltration and focal necrosis. More and more studies differentiated benign from malignant LNs with EUS; most of them were qualitative with elastographic histogram, using EUS-fine-needle aspiration biopsy (FNAB), histology, and/or surgical pathology as a reference standard.

Multiple studies have demonstrated that EUS and EBUS elastography can effectively identify the benign and malignant mediastinal and peritoneal LNs (Table 2) (47-51, 53-59). In addition, under the guidance of elastographic imaging, EUSFNAB or EBUS-FNAB can improve the positive rate of diagnosis and avoid false-positive results.

With qualitative analysis of elastographic histogram, elasticity pattern and SR have been studied to evaluate the stiffness of LNs. Giovannini et al. firstly evaluated the ability of EUS elastography to differentiate benign from malignant LNs with elasticity pattern in 2006 (56). In this color-coded scale of elastographic patterns, yellow means normal tissue, green fibrosis, red fat, and blue malignant tissue. They conducted a multicenter study in 2009 and found improved specificity of $82.5 \%$ compared with $50 \%$ in the previous study (47). What is more, the sensitivity, specificity, PPV, NPV, and global accuracy of EUS elastography were $91.8 \%$, $82.5 \%, 88.8 \%, 86.8 \%$, and $88.1 \%$, respectively, which were significantly better than the respective parameters of B-mode (56). In a study including 40 patients with a 4-point elasticity score, using the criteria of elasticity scores 1 and 2 as benign and elasticity scores 3 and 4 as malignant, the sensitivity, specificity, PPV, NPV, and diagnostic accuracy were $87.5 \%, 41.7 \%, 83.3 \%$, $50 \%$, and $60 \%$, respectively (53).

Besides, some researchers qualitatively classified EBUS elastograms into three patterns $(48,50,51)$ : pattern 1 , predominantly non-blue (green, yellow, and red); pattern 2, partly blue and non-blue (green, yellow, and red); and pattern 
TABLE 2 | The diagnostic performance of EUS or EBUS elastography in differentiating benign and malignant LNs.

\begin{tabular}{|c|c|c|c|c|c|c|c|c|c|}
\hline Study & Method & Study description & LN & $\begin{array}{l}\text { SE } \\
(\%)\end{array}$ & $\begin{array}{l}\text { SP } \\
(\%)\end{array}$ & $\begin{array}{l}\text { PPV } \\
(\%)\end{array}$ & $\begin{array}{l}\text { NPV } \\
(\%)\end{array}$ & Accuracy & Gold Standard \\
\hline Knabe, Surg Endosc (46) & EUS & Qualitative (3 patterns) & 40 & 100 & 64.1 & 75 & - & - & Cytology, histology \\
\hline Izumo, Jpn J Clin Oncol (48) & EBUS & Qualitative (3 patterns) & 75 & 100 & 92.3 & 94.6 & 100 & 96.7 & Histology \\
\hline Korrungruang P, Respirology (49) & EBUS & Qualitative (3 patterns) & 120 & 100 & 66.7 & 92.3 & 100 & 83 & Histology, surgical pathology \\
\hline $\begin{array}{l}\text { Ching-Kai Lin, Journal of the Formosan Medical } \\
\text { Association (50) }\end{array}$ & EBUS & Qualitative (3 patterns) & 206 & 64.7 & 85.6 & 71.6 & 81.3 & 78.2 & Histology, surgical pathology \\
\hline Fournier C, Bronchology Interv Pulmonol (51) & EBUS & Qualitative (3 patterns) & 217 & 87 & 68 & 80 & 77 & 80.7 & Histology \\
\hline $\begin{array}{l}\text { He, Journal of Central South University Medical } \\
\text { Sciences (52) }\end{array}$ & EBUS & Qualitative (4 patterns) & 68 & 85.7 & 76.9 & 85.7 & 76.9 & 82.3 & $\begin{array}{l}\text { Cytology, histology, surgical } \\
\text { pathology }\end{array}$ \\
\hline $\begin{array}{l}\text { Ahmed Youssef Altonbary, Diagn Ther Endosc } \\
\text { (53) }\end{array}$ & EUS & Qualitative (4 patterns) & 40 & 87.5 & 41.7 & 83.3 & 50 & 60 & Cytology, histology \\
\hline Giovannini, WJG (47) & EUS & $\begin{array}{l}\text { Qualitative (5 patterns), } \\
\text { multicenter }\end{array}$ & 101 & 91.8 & 82.5 & 88.8 & 86.8 & 88.1 & Cytology, histology \\
\hline Xu, Gastrointestinal Endoscopy (54) & EUS & Meta-analysis & 431 & 88 & 85 & - & - & 94.6 & Cytology, surgical pathology \\
\hline Korrungruang P, Respirology (49) & EBUS & Quantitative (SR $\geq 2.5$ ) & 120 & 100 & 70.8 & 93.2 & 100 & 85 & $\begin{array}{l}\text { Cytology, histology, surgical } \\
\text { pathology }\end{array}$ \\
\hline Hussein, Arab Journal of Gastroenterology (55) & EUS & Quantitative (SR $\geq 4.61)$ & 126 & 89.8 & 83.3 & 82.5 & 90.2 & - & $\begin{array}{l}\text { Cytology, histology, surgical } \\
\text { pathology }\end{array}$ \\
\hline $\begin{array}{l}\text { Ahmed Youssef Altonbary, Diagn Ther Endosc } \\
\text { (53) }\end{array}$ & EUS & Quantitative (SR $\geq 6.7$ ) & 40 & 99.9 & 57.1 & 99.9 & 64 & 77.5 & Cytology, histology \\
\hline
\end{tabular}

EUS, endoscopic ultrasound; EBUS, endobronchial ultrasound; LNs, lymph nodes; SE, sensitivity; SP, specificity; PPV, positive predictive value; NPV, negative predictive value; SR, strain ratio.

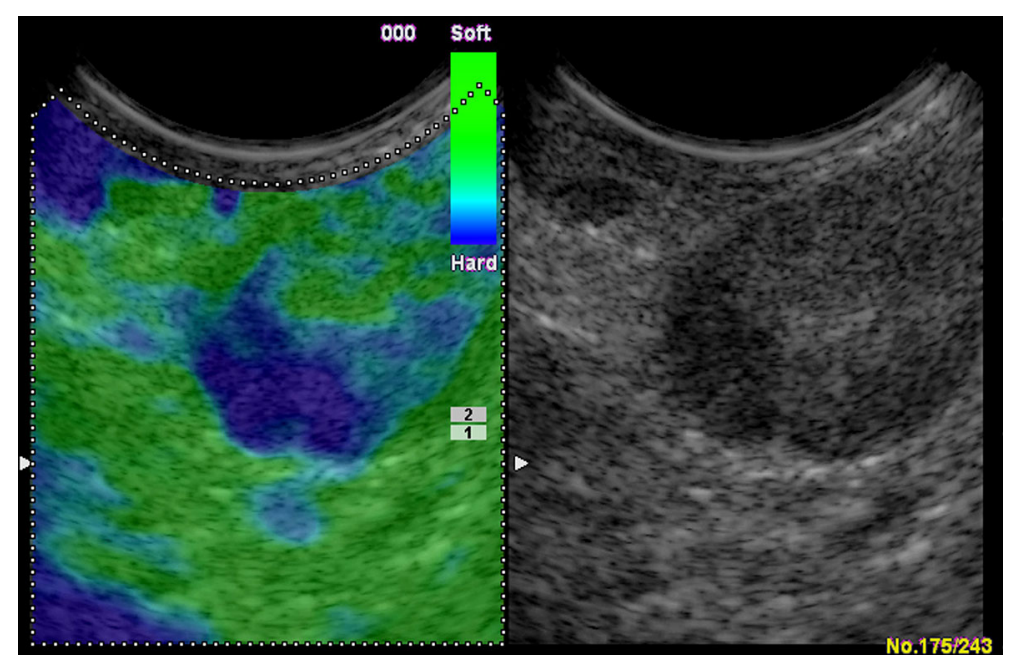

FIGURE 8 | Colorectal carcinoma with presacral circumscribed lymph node metastasis in endoscopic ultrasound. The strain elastography reveals a typically harder (blue) area in the lymph node.

3 , predominantly blue. With the use of the criteria of pattern 1 elastogram as benign and pattern 3 as malignant for differentiating malignant and benign mediastinal LNs with EBUS elastography, the sensitivity, specificity, PPV, NPV, and diagnostic accuracy were $90.6 \%, 82.6 \%, 71.6 \%, 94.7 \%$, and $85.2 \%$, respectively. But the central necrosis within malignant LNs and the fibrotic component within benign LNs may influence the accuracy of elastographic evaluations. What is more, the definitions of elastography patterns were subjective and may be hard to repeat by other researchers.

When judging malignant LNs with SR, previous research showed that with the cutoff point of SR $>2.5$, EUS elastography can differentiate benign from atypical malignant mediastinal LN sensitively (56). Okasha et al. reported that there were $89.8 \%$ sensitivity and $83.3 \%$ specificity in differentiating malignant LNs from benign ones with endoscopic UE while using the SR cutoff value $>4.61$ (55). Altonbary et al. found that the sensitivity, specificity, PPV, NPV, and diagnostic accuracy for differentiating benign LNs from malignant LNs were $57.1 \%, 99.9 \%, 99.9 \%, 64 \%$, and $77.5 \%$, respectively, with the mean SR cutoff value $>6.7$ (53). These studies reported the SR was more accurate than conventional EUS or EBUS, and EUS elastography combined with other sonomorphologic features is a potentially useful prognostic index differentiating malignant from benign 
TABLE 3 | Criteria on lymph node characterization using different ultrasound modes.

\begin{tabular}{|c|c|c|c|c|}
\hline $\begin{array}{l}\text { Lymphadenopathy } \\
\text { More (most) likely }\end{array}$ & Reactive lymph nodes & Malignant infiltration & Lymphoma & $\begin{array}{l}\text { Tuberculous } \\
\text { lymphadenitis }\end{array}$ \\
\hline B-mode & $\begin{array}{l}\text { Preserved architecture, } \\
\text { aspect ratio }>2 \text {, uniform } \\
\text { cortex }\end{array}$ & $\begin{array}{l}\text { Eccentric hypoechoic cortical } \\
\text { thickening, aspect ratio }<2 \text {, boundary } \\
\text { ambiguity, tissue edema around }\end{array}$ & $\begin{array}{l}\text { Destroyed architecture, focal or global hypoechoic } \\
\text { cortical thickening, usually without echogenic hilum, } \\
\text { approximate sphere, pseudocystic appearance }\end{array}$ & $\begin{array}{l}\text { Similar with } \\
\text { malignant } \\
\text { infiltration }\end{array}$ \\
\hline Color Doppler & Lymphatic vascular structure & $\begin{array}{l}\text { Peripheral or mixed vascularity, } \\
\text { vascular distortion }\end{array}$ & Rich vascularity & $\begin{array}{l}\text { Peripheral or } \\
\text { mixed } \\
\text { vascularity }\end{array}$ \\
\hline Vascular resistance & Lower, $\mathrm{Rl}<0.8, \mathrm{PI}<1.6$ & Higher, $\mathrm{RI}>0.8, \mathrm{PI}>1.6$ & Intermediate $\mathrm{RI}$ and $\mathrm{PI}$ & $\begin{array}{l}\mathrm{RI}<0.8, \mathrm{Pl}< \\
1.6\end{array}$ \\
\hline Strain elastography & $\begin{array}{l}1-2 \text { points in 4-point rating } \\
\text { elastography scale, } \mathrm{SR} \text { in } \\
\text { diffuse infiltration }<1.7\end{array}$ & SR in diffuse infiltration $>1.7$ & $\begin{array}{l}\text { Patterns } 1 \text { and } 2 \text { in five pattern elastographic score, } \\
\text { dynamic changes occur after treatment }\end{array}$ & No data \\
\hline $\begin{array}{l}\text { Shear wave-based } \\
\text { elastography }\end{array}$ & $\begin{array}{l}\text { No data, most often normal } \\
\text { architecture }\end{array}$ & Shear wave velocity $>3.03 \mathrm{~m} / \mathrm{s}$ & Shear wave velocity $>2.45 \mathrm{~m} / \mathrm{s}$ & No data \\
\hline
\end{tabular}

$R I$, resistive index; $P I$, pulsatility index; $S R$, strain ratio.

LNs (Figure 8). Besides, a meta-analysis found that the sensitivity and specificity of UE in differentiating benign and malignant LNs were $88 \%$ and $85 \%$, respectively (54).

However, the SR was generally calculated by two selected target regions, which makes it hard to precisely represent the stiffness of the whole LN. Thus, some studies used software to semiquantitatively analyze the color distribution of LN elastogram. Nakajima and his colleagues analyzed 49 LNs with stiff area ratio; they found that the sensitivity and specificity were $81 \%$ and $85 \%$, respectively, for predicting metastatic disease, using a cutoff value of 0.311 for stiff area ratios (57). Sun et al. used a software and transformed the elastographic image into gray scale, which varied form 0 (all red pixels) to 255 (all blue pixels). This method could calculate the mean gray value inside the target and reflect the stiffness of the targeted LN. They found that non-small cell lung cancer (NSCLC) showed a higher gray value than small cell lung cancer (SCLC) (201.33 versus 196.37) (58). Ma et al. found that the blue color proportion (BCP) of LNs containing benign diseases was higher than that of normal LNs containing lymphatic tissue $(33.3 \%, 49.0 \%$, and $42.9 \%$ versus $27.0 \%$ ), which revealed that the LN stiffness would increase in some diseases with a higher density of cells and vessels, like granulomas and pulmonary infection. These LNs might show the features of metastatic LNs if assessed solely by EUS elastography. However, the BCP in malignant LNs was remarkably higher than benign LNs ( $\mathrm{p}<0.001,57.1 \%$ versus $31.1 \%$ ). The highest average BCP was shown in lung squamous cell carcinoma (71.6\%) (59).

According to published studies on the qualitative EBUS elastography in differentiating benign from malignant LNs, Korrungruang et al. found that two methods had similar diagnostic performances (49), but Lin et al. considered that qualitative EBUS elastography may be more suitable for clinical practice (50).

In the future, more studies should be conducted to compare the qualitative and quantitative EUS elastography in differentiating benign from malignant LNs, in order to find a more suitable, accurate method for clinical practice.

\section{CONCLUSION}

UE is a promising method for measuring tissue hardness and has been widely used in differentiating reactive LNs, lymphoma, metastatic LNs, and other lymphadenopathy. Besides, EUS and EBUS elastography are non-invasive techniques and have been proven to be able to provide complementary stiff information for conventional EUS imaging; the positive rate of diagnosis of EUSFNAB or EBUS-FNAB can be improved under the guidance of elastographic imaging. There are some studies that used elastography in cervical, axillary, mediastinal, and peritoneal LNs, but further studies with unbiased large-scale samples in different sites are still required. Also, the direct comparison between qualitative and quantitative elastography and new solutions for current elastographic limitations should be pursued. The current consensus for LNs diagnosis is that no single parameter has sufficient diagnostic performance, and the combination of UE and traditional US technology is conducive to the differential diagnosis of LNs (Table 3). In conclusion, UE can aid in the differentiation of benign and malignant LNs and has immense potential clinical values.

\section{AUTHOR CONTRIBUTIONS}

Conception and design: A-JY, X-WC, and CD. Drafting of the article: BW, QG, and YY. Critical revision of the article for important intellectual content: BW, QG, and J-YW. All authors contributed to the article and approved the submitted version.

\section{FUNDING}

This work was supported by the Science and Technology Department of Hunan Province under Grant No. 2020SK52705. 


\section{REFERENCES}

1. Cosgrove D, Piscaglia F, Bamber J, Bojunga J, Correas JM, Gilja OH, et al. EFSUMB. EFSUMB Guidelines and Recommendations on the Clinical Use of Ultrasound Elastography. Part 2: Clinical Applications. Ultraschall Med (2013) 34(3):238-53. doi: 10.1055/s-0033-1335375

2. Bhatia KS, Cho CC, Yuen YH, Rasalkar DD, King AD, Ahuja AT. Real-Time Qualitative Ultrasound Elastography of Cervical Lymph Nodes in Routine Clinical Practice: Interobserver Agreement and Correlation With Malignancy. Ultrasound Med Biol (2010) 36(12):1990-7. doi: 10.1016/j.ultrasmedbio. 2010.08.016

3. Tan R, Xiao Y, He Q. Ultrasound Elastography: Its Potential Role in Assessment of Cervical Lymphadenopathy. Acad Radiol (2010) 17(7):84955. doi: 10.1016/j.acra.2010.03.014

4. Chen BD, Xu HX, Zhang YF, Liu BJ, Guo LH, Li DD, et al. The Diagnostic Performances of Conventional Strain Elastography (SE), Acoustic Radiation Force Impulse (ARFI) Imaging and Point Shear-Wave Speed (pSWS) Measurement for non-Calcified Thyroid Nodules. Clin Hemorheol Microcirc (2017) 65(3):259-73. doi: 10.3233/CH-16178

5. Dong Y, Wang WP, Xu Y, Cao J, Mao F, Dietrich CF. Point Shear Wave Speed Measurement in Differentiating Benign and Malignant Focal Liver Lesions. Med Ultrasonography (2017) 19(3):259-64. doi: 10.11152/mu-1142

6. Ozkan MB, Bilgici MC, Eren E, Caltepe G, Yilmaz G, Kara C, et al. Role of Point Shear Wave Elastography in the Determination of the Severity of Fibrosis in Pediatric Liver Diseases With Pathologic Correlations. J Ultrasound Med: Off J Am Inst Ultrasound Med (2017) 36(11):2337-44. doi: 10.1002/jum.14277

7. Bamber J, Cosgrove D, Dietrich CF, Fromageau J, Bojunga J, Calliada F, et al. EFSUMB Guidelines and Recommendations on the Clinical Use of Ultrasound Elastography. Part 1: Basic Principles and Technology. Ultraschall der Med (2013) 34(2):169-84. doi: 10.1055/s-0033-1335205

8. Bhatia KS, Lee YY, Yuen EH, Ahuja AT. Ultrasound Elastography in the Head and Neck. Part II. Accuracy for Malignancy. Cancer imaging: Off Publ Int Cancer Imaging Soc (2013) 13(2):260-76. doi: 10.1102/1470-7330.2013.0027

9. Yoon JH, Jung HK, Lee JT, Ko KH. Shear-Wave Elastography in the Diagnosis of Solid Breast Masses: What Leads to False-Negative or False-Positive Results? Eur Radiol (2013) 23(9):2432-40. doi: 10.1007/s00330-013-2854-6

10. Kim SJ, Ko KH, Jung HK, Kim H. Shear Wave Elastography: Is It a Valuable Additive Method to Conventional Ultrasound for the Diagnosis of Small $(</=2 \mathrm{Cm})$ Breast Cancer? Medicine (2015) 94(42):e1540. doi: 10.1097/ MD.0000000000001540

11. Lyshchik A, Higashi T, Asato R, Tanaka S, Ito J, Hiraoka M, et al. Cervical Lymph Node Metastases: Diagnosis at Sonoelastography-Initial Experience. Radiology (2007) 243(1):258-67. doi: 10.1148/radiol.2431052032

12. Leyla A, Suna Özhan O, Rusen A. Value of Ultrasound Elastography in the Differential Diagnosis of Cervical Lymph Nodes. J Ultrasound Med (2016) 35:2491-9. doi: 10.7863/ultra.15.09019

13. Özel D, Özel B. Evaluation of Diagnostic Value of Conventional and Color Doppler Ultrasound With Elastography Strain Ratios in Diffierentiation Between Benign and Malignant Lymph Nodes. Pol J Radiol (2018) 83:3236. doi: 10.5114/pjr.2018.73293

14. Lo WC, Cheng PW, Wang CT, Liao LJ. Real-Time Ultrasound Elastography: An Assessment of Enlarged Cervical Lymph Nodes. Eur Radiol (2013) 23 (9):2351-7. doi: 10.1007/s00330-013-2861-7

15. Onol S, Ozkaya O. Diagnostic Value of Real-Time Elastography in Diagnosing Lymph Node Metastasis of Skin Cancer. Cureus (2020) Oct 1712(10):e10997. doi: 10.7759/cureus.10997

16. Tsai WC, Lin CK, Wei HK, Yu BL, Hung CF, Cheng SH, et al. Sonographic Elastography Improves the Sensitivity and Specificity of Axilla Sampling in Breast Cancer: A Prospective Study. Ultrasound Med Biol (2013) 39(6):941-9. doi: 10.1016/j.ultrasmedbio.2012.12.013

17. Xu Y, Bai X, Chen Y, Jiang L, Hu B, Hu B, et al. Application of Real-Time Elastography Ultrasound in the Diagnosis of Axillary Lymph Node Metastasis in Breast Cancer Patients. Sci Rep (2018) 8(1):10234. doi: 10.1038/s41598-018-28474-y

18. Pehlivan M, Gurbuz MK, Cingi C, Adapinar B, Değirmenci AN, Acikalin FM, et al. Diagnostic Role of Ultrasound Elastography on Lymph Node Metastases in Patients With Head and Neck Cancer. Braz J Otorhinolaryngol (2019) 85 (3):297-302. doi: 10.1016/j.bjorl.2018.01.002
19. Zhang F, Zhao X, Ji X, Han R, Li P, Du M. Diagnostic Value of Acoustic Radiation Force Impulse Imaging for Assessing Superficial Lymph Nodes A Diagnostic Accuracy Study. Med (Baltimore) (2017) 96(43):e8125. doi: 10.1097/MD.0000000000008125

20. Lenghel LM, Bolboaca SD, Botar-Jid C, Baciut G, Dudea SM. The Value of a New Score for Sonoelastographic Differentiation Between Benign and Malignant Cervical Lymph Nodes. Med Ultrasonography (2012) 14(4):271-7.

21. Fujiwara T, Tomokuni J, Iwanaga K, Ooba S, Haji T. Acoustic Radiation Force Impulse Imaging for Reactive and Malignant/Metastatic Cervical Lymph Nodes. Ultrasound Med Biol (2013) 39(7):1178-83. doi: 10.1016/ j.ultrasmedbio.2013.02.001

22. Meng W, Xing P, Chen Q, Wu C. Initial Experience of Acoustic Radiation Force Impulse Ultrasound Imaging of Cervical Lymph Nodes. Eur J Radiol (2013) 82(10):1788-92. doi: 10.1016/j.ejrad.2013.05.039

23. Azizi G, Keller JM, Mayo ML, Piper K, Puett D, Earp KM, et al. Shear Wave Elastography and Cervical Lymph Nodes: Predicting Malignancy. Ultrasound Med Biol (2016) 42(6):1273-81. doi: 10.1016/j.ultrasmedbio.2016.01.012

24. Bayramoglu Z, Caliskan E, Karakas Z, Karaman S, Tugcu D, Somer A, et al. Diagnostic Performances of Superb Microvascular Imaging, Shear Wave Elastography and Shape Index in Pediatric Lymph Nodes Categorization: A Comparative Study. Br J Radiol (2018) 91(1087):20180129. doi: 10.1259/ bjr.20180129

25. Luo S, Yao G, Hong Z, Zhang S, Wang W, Zhang J, et al. Qualitative Classification of Shear Wave Elastography for Differential Diagnosis Between Benign and Metastatic Axillary Lymph Nodes in Breast Cancer. Front Oncol (2019) 9. doi: 10.3389/fonc.2019.00533

26. Ng WL, Omar N, Ab Mumin N, Ramli Hamid MT, Vijayananthan A, Rahmat K. Diagnostic Accuracy of Shear Wave Elastography as an Adjunct Tool in Detecting Axillary Lymph Nodes Metastasis. Acad Radiol (2021) S1076-6332 (21):00138-0. doi: 10.1016/j.acra.2021.03.018

27. Ishibashi N, Yamagata K, Sasaki H, Seto K, Shinya Y, Ito H, et al. Real-Time Tissue Elastography for the Diagnosis of Lymph Node Metastasis in Oral Squamous Cell Carcinoma. Ultrasound Med Biol (2012) 38(3):389-95. doi: 10.1016/j.ultrasmedbio.2011.12.004

28. Desmots F, Fakhry N, Mancini J, Reyre A, Vidal V, Jacquier A, et al. Shear Wave Elastography in Head and Neck Lymph Node Assessment: Image Quality and Diagnostic Impact Compared With B-Mode and Doppler Ultrasonography. Ultrasound Med Biol (2016) 42(2):387-98. doi: 10.1016/ j.ultrasmedbio.2015.10.019

29. Youk JH, Son EJ, Kim JA, Gweon HM. Pre-Operative Evaluation of Axillary Lymph Node Status in Patients With Suspected Breast Cancer Using Shear Wave Elastography. Ultrasound Med Biol (2017) 43(8):1581-6. doi: 10.1016/ j.ultrasmedbio.2017.03.016

30. Klıç A, Çolakoğlu Er H. Virtual Touch Tissue Imaging Quantification Shear Wave Elastography for Determining Benign Verus Malignant Cervical Lymph Nodes: A Comparison With Conventional Ultrasound. Diagn Interv Radiol (2019) 25:114-21. doi: 10.5152/dir.2019.18406

31. Cong R, Li J, Guo S. A New Qualitative Pattern Classification of Shear Wave Elastograghy for Solid Breast Mass Evaluation. Eur J Radiol (2017) 87:111-9. doi: 10.1016/j.ejrad.2016.12.021

32. Huang XW, Huang QX, Huang H, Cheng MQ, Tong WJ, Xian MF, et al. Diagnostic Performance of Quantitative and Qualitative Elastography for Axillary Lymph Node Metastasis in Breast Cancer: A Systematic Review and Meta-Analysis. Front Oncol (2020) 10:552177. doi: 10.3389/fonc.2020.552177

33. Torre LA, Bray F, Siegel RL, Ferlay J, Lortet-Tieulent J, Jemal A. Global Cancer Statistics, 2012. Cancer J Clin (2015) 65(2):87-108. doi: 10.3322/caac.21262

34. Alam F, Naito K, Horiguchi J, Fukuda H, Tachikake T, Ito K. Accuracy of Sonographic Elastography in the Differential Diagnosis of Enlarged Cervical Lymph Nodes: Comparison With Conventional B-Mode Sonography. AJR Am J Roentgenol (2008) 191(2):604-10. doi: 10.2214/AJR.07.3401

35. Lenghel LM, Botar Jid C, Bolboaca SD, Ciortea C, Vasilescu D, Baciut G, et al. Comparative Study of Three Sonoelastographic Scores for Differentiation Between Benign and Malignant Cervical Lymph Nodes. Eur J Radiol (2015) 84 (6):1075-82. doi: 10.1016/j.ejrad.2015.02.017

36. Turgut E, Celenk C, Tanrivermis Sayit A, Bekci T, Gunbey HP, Aslan K. Efciency of B-Mode Ultrasound and Strain Elastography in Diffierentiating Between Benign and Malignant Cervical Lymph Nodes. Ultrasound Q (2017) 33:201-7. doi: 10.1097/RUQ.0000000000000302 
37. Squillaci E, Antonicoli M, Manenti G, Bolacchi F. Real-Time Ultrasound Elastography for Assessment of Response to Brentuximab Vedotin Treatment in Relapsed and Refractory Hodgkin Lymphoma. Eur Rev Med Pharmacol Sci (2016) 20(8):1628-35.

38. Chae SY, Jung HN, Ryoo I, Suh S. Differentiating Cervical Metastatic Lymphadenopathy and Lymphoma by Shear Wave Elastography. Sci Rep (2019) 9(1):12396. doi: 10.1038/s41598-019-48705-0

39. Youdong K, KYung Hee K, Hae KYoung J, HYun Ju L. Shear-Wave Elastography Features of Primary Non-Hodgkin's Lymphoma of the Breast: A Case Report and Literature Review. J Clin Diagn Res (2016) 10(12):TD01-3. doi: 10.7860/JCDR/2016/22612.9062

40. Fu Y, Shi YF, Yan K, Wang YJ, Yang W, Feng GS. Clinical Value of Real Time Elastography in Patients With Unexplained Cervical Lymphadenopathy: Quantitative Evaluation. Asian Pac J Cancer Prev (2014) 15(13):5487-92. doi: 10.7314/APJCP.2014.15.13.5487

41. Cheng KL, Choi YJ, Shim WH, Lee JH, Baek JH. Virtual Touch Tissue Imaging Quantification Shear Wave Elastography: Prospective Assessment of Cervical Lymph Nodes. Ultrasound Med Biol (2016) 42:378-86. doi: 10.1016/ j.ultrasmedbio.2015.10.003

42. Baik J, Lee KH, Ryu J, Kim O, Yoon JH, Kim SH, et al. Role of Real-Time Elastography in the Evaluation of Cervical Lymph Nodes in Patients With Kikuchi Disease. Ultrasound Med Biol (2016) 42(9):2334-40. doi: 10.1016/ j.ultrasmedbio.2016.05.009

43. Qin Q, Wang D, Xu L, Lan Y, Tong M. Evaluating Lymph Node Stiffness to Differentiate Bacterial Cervical Lymphadenitis and Lymph Node-First Presentation of Kawasaki Disease by Shear Wave Elastography. J Ultrasound Med (2020) 40(7):1371-80. doi: 10.1002/jum.15518

44. Saftoiu A, Vilmann P, Ciurea T, Popescu GL, Iordache A, Hassan H, et al. Dynamic Analysis of EUS Used for the Diffierentiation of Benign and Malignant Lymph Nodes. Gastrointest Endosc (2007) 66:291-300. doi: 10.1016/j.gie.2006.12.039

45. Barr RG, Nakashima K, Amy D, Cosgrove D, Farrokh A, Schafer F, et al. WFUMB Guidelines and Recommendations for Clinical Use of Ultrasound Elastography: Part 2: Breast. Ultrasound Med Biol (2015) 41:1148-60. doi: 10.1016/j.ultrasmedbio.2015.03.008

46. Knabe M, Günter E, Ell C, Pech O. Can EUS Elastography Improve Lymph Node Staging in Esophageal Cancer? Surg Endosc (2013) 27(4):1196-202. doi: 10.1007/s00464-012-2575-y

47. Giovannini M, Thomas B, Erwan B, Christian P, Fabrice C, Benjamin E, et al. Endoscopic Ultrasound Elastography for Evaluation of Lymph Nodes and Pancreatic Masses: A Multicenter Study. World J Gastroenterol (2009) 15 (13):1587-93. doi: 10.3748/wjg.15.1587

48. Izumo T, Sasada S, Chavez C, Matsumoto Y, Tsuchida T. Endobronchial Ultrasound Elastography in the Diagnosis of Mediastinal and Hilar Lymph Nodes. Jpn J Clin Oncol (2014) 44:956e62. doi: 10.1093/jjco/hyu105

49. Korrungruang P, Boonsarngsuk V. Diagnostic Value of Endobronchial Ultrasound Elastography for the Differentiation of Benign and Malignant Intrathoracic Lymph Nodes. Respirology (2017) 22(5):972-7. doi: 10.1111/resp.12979

50. Lin CK, Yu KL, Chang LY, Fan HJ, Wen YF, Ho CC. Differentiating Malignant and Benign Lymph Nodes Using Endobronchial Ultrasound Elastography. J Formos Med Assoc (2019) 118(1 Pt 3):436-43. doi: 10.1016/ j.jfma.2018.06.021
51. Fournier C, Dhalluin X, Wallyn F, Machuron F, Bouchindhomme B, Copin $\mathrm{MC}$, et al. Performance of Endobronchial Ultrasound Elastography in the Differentiation of Malignant and Benign Mediastinal Lymph Nodes: Results in Real-Life Practice. J Bronchol Interv Pulmonol (2019) 26(3):193-8. doi: 10.1097/LBR.0000000000000551

52. He H, Lu X, Ma H, Zhu J, Huang M. Value of Endobronchial Ultrasound Elastography in the Diagnosis of Mediastinal and Hilar Lymph Node Metastasis in Lung Cancer. Zhong Nan Da Xue Xue Bao Yi Xue Ban (2016) 41(1):30-6. doi: 10.11817/j.issn.1672-7347.2016.01.005

53. Altonbary AY, Hakim H, El-Shamy AM. Endoscopic Ultrasound Elastography for Evaluation of Lymph Nodes: A Single Center Experience. Diagn Ther Endosc (2018) 2018:7186341. doi: 10.1155/2018/7186341

54. Xu W, Shi J, Zeng X, Li X, Xie WF, Guo J, et al. EUS Elastography for the Differentiation of Benign and Malignant Lymph Nodes: A Meta-Analysis. Gastrointestinal Endoscopy (2011) 74(5):1001-9quiz 1115 e1001-1004. doi: 10.1016/j.gie.2011.07.026

55. Okasha H, Elkholy S, Sayed M, El-Sherbiny M, El-Hussieny R, El-Gemeie E, et al. Ultrasound, Endoscopic Ultrasound Elastography, and the Strain Ratio in Differentiating Benign From Malignant Lymph Nodes. Arab J Gastroenterol (2018) 19(1):7-15. doi: 10.1016/j.ajg.2018.01.001

56. Giovannini M, Hookey LC, Bories E, Pesenti C, Monges G, Delpero JR. Endoscopic Ultrasound Elastography: The Frst Step Towards Virtual Biopsy? Preliminary Results in 49 Patients. Endoscopy (2006) 38(4):344-8. doi: $10.1055 / \mathrm{s}-2006-925158$

57. Nakajima $T$, Inage $T$, Sata $Y$, Morimoto J, Tagawa $T$, Suzuki $H$, et al. Elastography for Predicting and Localizing Nodal Metastases During Endobronchial Ultrasound. Respiration (2015) 90(6):499-506. doi: 10.1159/ 000441798

58. Sun J, Zheng X, Mao X, Wang L, Xiong H, Herth FJF, et al. Endobronchial Ultrasound Elastography for Evaluation of Intrathoracic Lymph Nodes: A Pilot Study. Respiration (2017) 93(5):327-38. doi: 10.1159/000464253

59. Ma H, An Z, Xia P, Cao J, Gao Q, Ren G, et al. Semi-Quantitative Analysis of EBUS Elastography as a Feasible Approach in Diagnosing Mediastinal and Hilar Lymph Nodes of Lung Cancer Patients. Sci Rep (2018) 8(1):3571. doi: 10.1038/s41598-018-22006-4

Conflict of Interest: The authors declare that the research was conducted in the absence of any commercial or financial relationships that could be construed as a potential conflict of interest.

Publisher's Note: All claims expressed in this article are solely those of the authors and do not necessarily represent those of their affiliated organizations, or those of the publisher, the editors and the reviewers. Any product that may be evaluated in this article, or claim that may be made by its manufacturer, is not guaranteed or endorsed by the publisher.

Copyright (c) 2021 Wang, Guo, Wang, Yu, Yi, Cui and Dietrich. This is an open-access article distributed under the terms of the Creative Commons Attribution License (CC BY). The use, distribution or reproduction in other forums is permitted, provided the original author(s) and the copyright owner(s) are credited and that the original publication in this journal is cited, in accordance with accepted academic practice. No use, distribution or reproduction is permitted which does not comply with these terms. 